\title{
Truvada (emtricitabine/tenofovir) pre-exposure prophylaxis roll-out among South African university students: Lots of positives, but let us keep an eye on possible surprises
}

\author{
K Montjane, ${ }^{1}$ BSc, BHSc; S Dlamini, ${ }^{2}$ MB ChB, FCP (SA), Cert ID (SA); C Dandara, ${ }^{1}$ BSc Hons, PhD \\ ${ }^{1}$ Pharmacogenetics Research Group, Division of Human Genetics, Department of Pathology and Institute of Infectious Disease and Molecular \\ Medicine, Faculty of Health Sciences, University of Cape Town, South Africa \\ ${ }^{2}$ Division of Infectious Disease and HIV Medicine, Department of Medicine, Groote Schuur Hospital and Faculty of Health Sciences, \\ University of Cape Town, South Africa
}

Corresponding author: C Dandara (collet.dandara@uct.ac.za)

\begin{abstract}
Antiretroviral therapy (ART) has fundamentally altered the natural history of HIV/AIDS, sharply reducing HIV-related morbidity and prolonging longevity. However, there seems to be a resurgence in HIV infection rates in some parts of the world that has prompted consideration of pre-exposure prophylaxis (pre-EP) and vaccination. Despite their good viral suppression profiles, most drugs used as part of ART also have unwanted adverse drug reactions/effects (ADRs). In this article we acknowledge the utility of pre-EP in combating HIV transmission, but we also highlight the need to prepare for management of other unexpected outcomes such as ADRs and viral resistance, to ensure the success of the programme.
\end{abstract}

S Afr Med J 2018;108(2):79-81. DOI:10.7196/SAMJ.2018.v108i2.13035

Truvada is an antiretroviral (ARV) pill that combines two ARV drugs, tenofovir disoproxil fumarate (TDF) and emtricitabine (FTC), and has well-established efficacy in reducing the risk of contracting HIV if taken daily. Data from the South African (SA) Human Sciences Research Council show that women aged 15 - 25 years are most at risk of contracting HIV. ${ }^{[1]}$ This report appears to have been one of the catalysts in prompting the Higher Education and Training HIV/ AIDS Programme (HEAIDS) and the National Department of Health to roll out Truvada to university and college students, because of the overlap with this high-risk age group. It is important to note that many studies with Truvada and preventive vaginal gels, involving thousands of women, have failed in SA and other Southern African Development Community countries. ${ }^{[2,3]}$ These studies include trials such as FACTS and VOICE, ${ }^{[4-6]}$ and it is thought that failure was due to lack of adherence and not ineffectiveness. The roll-out of Truvada therefore aims to offer protection to students at risk of HIV infection, in the hope that they will have better adherence, and has been extended to HIV-negative students across nine institutions of higher learning across SA. According to the director of HEAIDS, university students represent a group in which high rates of transactional sex occur, coupled with a low uptake of condoms (HEAIDS press release, 27 September 2017).

It has been noted that transactional sex with so-called 'sugar daddies'/'blessers' is a significant risk factor and social driver in the context of HIV infection among young people. ${ }^{[7]}$ Relationships marked by age and material differences are increasingly common among university students and may involve exposure to unsafe sexual practices, among other things ${ }^{[8]}$ Truvada intervention will empower mostly young women to be in control of their infection status, as HIV prevalence and incidence rates remain disproportionately higher in females than in males. ${ }^{[9]}$ However, as much as Truvuda is a potentially useful intervention, little is known about the drivers of product acceptability to end-users of such methods for HIV prevention. In a study that explored the end-user's product preference for multipurpose prevention technology delivery forms in SA and Kenya, it was found that only $27 \%$ of women aged 18 - 30 years preferred the Truvada. ${ }^{[10]}$ This is the age group into which most of the college and university students who are the target for Truvada roll-out fall. It is evident that we need to ask some questions: (i) is there sufficient evidence that college and university students will have better adherence than participants enrolled in previous studies in this country? (ii) since one of the drivers of uptake and adherence is perception of HIV risk, how certain are we that the college and university students perceive their risk as high? and (iii) lastly, as evidence shows that pre-exposure prophylaxis (pre-EP) is more likely to succeed if its roll-out is combined with interventions that target social drivers of HIV vulnerability specific to college and university students, will such interventions also be rolled out?

There has been particular interest in Truvada since announcement of the roll-out, owing to its effectiveness profile. There is no doubt that if it is taken correctly, with optimal adherence, there is a huge potential to reduce numbers of new infections, estimated as more than 250000 in the year 2016. ${ }^{[1]}$ What this article seeks to highlight is that, despite the many positives, we should also be aware of possible surprises consequent to Truvada roll-out in healthy, HIVnegative young people. These are some of the questions we need to ask: (i) what are the possible effects of non-compliance with Truvada? (ii) what would be the consequences to participants who start off negative and are then infected, but continue to take Truvada intermittently? (iii) what are the possibilities of inducing resistance to Truvada in this young sexually active population? and (iv) what effect is Truvada pre-EP likely to have on attitudes of sexually 
active people to other sexually transmitted diseases or infections? Furthermore, how prepared is our healthcare system to handle and manage the multifaceted challenges that will potentially arise from the roll-out in the nine institutions? Massive simultaneous roll-out of awareness programmes to educate on possible consequences of nonadherence, and training of healthcare practitioners to handle this new phenomenon of Truvada preEP, are necessary.

\section{Possible long-term effects}

It is important to note that both TDF and FTC have documented adverse effects (adverse drug reactions, or ADRs). A meta-analysis by Siemieniuk et al. ${ }^{[12]}$ showed that TDF/FTC was associated with stillbirth/early neonatal death and early premature delivery in HIVpositive participants, although there were no data on HIV-negative participants. Several studies have reported that another effect of the two drugs is lowering bone mineral density, ${ }^{[13,14]}$ so an additional concern is the possible long-term effects of Truvada pre-EP on the general health of the population. Surveillance of ADRs and related toxicities remains a challenge in the public health sectors of developing countries, ${ }^{[15]}$ mainly owing to lack of coherent structures or systems for pharmacovigilance and drug surveillance that track, assess and monitor safety profiles of ARVs. Patients on ARV therapy (ART) are usually monitored through a spontaneous surveillance method that is currently inefficient in detecting ADRs. ${ }^{[15]}$ In resourcelimited health sectors like that of SA, pre-EP for healthy individuals will compete for scarce resources that are failing to contain a growing disease burden.

\section{What about the cost?}

In September 2016, SA started to implement the World Health Organization (WHO) evidence-based guidelines for universal test and treat (UTT). This strategy aims to test $90 \%$ of infected people, treat $90 \%$ of those tested, and have viral loads suppressed in $90 \%$ of individuals treated. SA already has one of the biggest ART programmes in the world, mostly funded by the fiscus, and implementation of UTT will significantly increase the number of people on ART. An increase in the budget will therefore be required in an already unfavourable economic climate. UTT will undoubtedly push demand for healthcare services in a context of a double burden of disease, high demand for medical personnel, and inadequate infrastructure. Public hospitals are already barely coping with the influx of patients, with complaints including medication stock-outs and sluggish financial support from donors, whose contribution has flatlined for the past 6 years. ${ }^{[16]}$ To add a huge number of sexually active but healthy people to this overburdened healthcare platform would hasten its further deterioration.

TDF has been associated with severe nephrotoxicity, changes in markers of renal function, serious renal adverse events, and decreases in bone mineral density. ${ }^{[17]}$ It should also be taken into consideration that most data on TDF ADRs are from controlled trials in populations that are genetically different from much of SA's student population. Furthermore, many individuals in resource-limited settings use a dual system of healthcare, traditional and conventional. With an estimated 26.6 million users of traditional medicine in SA, ${ }^{[18]}$ new drug-herb interactions are likely to emerge.

The challenges that policies such as UTT pose for developing countries have been well outlined, and have been predicted for sub-Saharan Africa (SSA). ${ }^{[19,20]}$ The same challenges outlined by Bigna and colleagues ${ }^{[19,20]}$ are applicable in the roll-out of Truvada to healthy individuals in SA. It was concluded that SSA cannot afford UTT, and in this case it is our submission that SA cannot afford the cost and implications of Truvada roll-out. SSA should always strategise in implementing WHO policies, factoring in local resource constraints. ${ }^{[19]}$ We do not want to believe that Truvada roll-out is influenced by pharmaceutical companies that stand to gain regardless of the consequences to the country.

There is no doubt that Truvada roll-out will require additional resources, so for a successful outcome, funds need to be made available in a sustainable manner. Total health expenditure is predicted to reach almost $10 \%$ of the gross domestic product in SA by 2017/18, amounting to a staggering USD12 billion (ZAR178 billion). ${ }^{[21]}$ In the 2017 budget, the SA National Treasury allocated an additional USD63 million (ZAR885 million) to the response to HIV, in particular the implementation of UTT. ${ }^{[22]}$ However, SA still faces a flood of new HIV infections, with an estimated 266618 in 2016. ${ }^{[11]}$

\section{Conclusion}

Generally, ART has been associated with ADRs, and exposing healthy individuals to Truvada could put them at risk of renal failure and other complications. ${ }^{[20]}$ It is our opinion that, as we look at the positive side of Truvada roll-out, due care should be taken in its implementation, as there are environmental and genomic factors specific to SA populations. We write this letter in the hope that as the Truvada pre-EP programme is rolled out, appropriate preparations are made to ensure its success and possible mitigation measures put in place to ameliorate the negatives.

\section{Acknowledgements. None.}

Author contributions. KM: co-conceptualised the idea, wrote the first draft, corrected, commented on all subsequent drafts and approved the final draft. SD: commented on all drafts, especially clinical aspects, and approved the final version of the manuscript. CD: conceptualised the idea, supervised KS in writing the first and subsequent drafts, commented on all drafts, approved the final version and submitted to the journal on behalf of co-authors.

Funding. CD's research group is funded by the South African Medical Research Council (SAMRC) and the National Research Foundation. KS has a bursary with the SAMRC.

Conflicts of interest. None.

1. Zuma K, Shisana O, Rehle TM, et al. New insights into HIV epidemic in South Africa: Key findings from the National HIV Prevalence, Incidence and Behaviour Survey, 2012. Afr J AIDS Res 2016;15(1):67-75. https://doi.org/10.2989/16085906.2016.1153491

2. Van Damme L, Corneli A, Ahmed K, et al. Preexposure prophylaxis for HIV infection among African . Van Damme L, Corneli A, Ahmed K, et al. Preexposure prophylaxis for HIV infection
women. N Engl J Med 2012;367(5):411-422. https://doi.org/10.1056/NEJMoa1202614

3. Van der Straten A, van Damme L, Haberer JE, Bangsberg DR. Unraveling the divergent results of preexposure prophylaxis trials for HIV prevention. AIDS 2012;26(7):F13-F19. https://doi.org/10.1097/ QAD.0b013e3283522272

4. Abdool Karim Q, Abdool Karim SS, Frohlich JA, et al. Effectiveness and safety of tenofovir gel, an antiretroviral microbicide, for the prevention of HIV infection in women. Science 2010;329(5996): 11681174. https://doi.org/10.1126/science.1193748

5. Anderson PL, Glidden DV, Liu A, et al. Emtricitabine-tenofovir concentrations and pre-exposure prophylaxis efficacy in men who have sex with men. Science Transl Med 2012;4(151):151ra25. https:// doi.org/10.1126/scitranslmed.3004006

6. Marrazzo JM, Ramjee G, Richardson BA, et al. Tenofovir-based preexposure prophylaxis for HIV infection among African women. N Engl J Med 2015;372(6):509-518. https://doi.org/10.1056/ NEJMoal 402269

. Shisana O, Rehle T, Simbayi LC, et al. and the SABSSM III Implementation Team. South African National HIV Prevalence, Incidence, Behaviour and Communication Survey 2008: A Turning Tide among Teenagers? Cape Town: HSRC Press, 2009. http://hdl.handle.net/20.500.11910/4803 (accessed 1 January 2017)

8. Shefer T, Clowes L, Vergnani T. Narratives of transactional sex on a university campus. Cult Health Sex 2012;14(4):435-447. https://doi.org/10.1080/13691058.2012.664660

9. Gomez-Olive FX, Angotti N, Houle B, et al. Prevalence of HIV among those 15 and older in rural South Africa. AIDS Care 2013;25(9):1122-1128. https://doi.org/10.1080/09540121.2012.750710

10. Weinrib R, Minnis A, Agot K, et al. End-users' product preference across three multipurpose prevention technology delivery forms: Baseline results from young women in Kenya and South Africa. AIDS Behav 2017;21:1-13. https://doi.org/10.1007/s10461-017-1911-6

11. Johnson LF, Chiu C, Myer L, et al. Prospects for HIV control in South Africa: A model-based analysis. Glob Health Action 2016;9:30314. https://doi.org/10.3402/gha.v9.30314

12. Siemieniuk RA, Foroutan F, Mirza R, et al. Antiretroviral therapy for pregnant women living with HIV or hepatitis B: A systematic review and meta-analysis. BMJ Open 2017;7(9):e019022. https://doi. org/10.1136/bmjopen-2017-019022 
13. Purdy JB, Gafni RI, Reynolds JC, Zeichner S, Hazra R. Decreased bone mineral density with off-label use of tenofovir in children and adolescents infected with human immunodeficiency virus. J Pediatr 2008;152(4):582-584. https://doi.org/10.1016/j.jpeds.2007.12.020

14. McComsey GA, Kitch D, Daar ES, et al. Bone mineral density and fractures in antiretroviral-naive persons randomized to receive abacavir-lamivudine or tenofovir disoproxil fumarate-emtricitabine persons randomized to receive abacavir-lamivudine or tenofovir disoproxil fumarate-emtricitabine
along with efavirenz or atazanavir-ritonavir: AIDS Clinical Trials Group A5224s, a substudy of ACTG A5202. J Infect Dis 2011;203(12):1791-1801. https://doi.org/10.1093/infdis/jir188

15. Masenyetse LJ, Manda SO, Mwambi HG. An assessment of adverse drug reactions among HIV positive patients receiving antiretroviral treatment in South Africa. AIDS Res Ther 2015;12:6. https://doi. patients receiving antiretroviral treatment in South Africa. AIDS Res Ther 2015;12:6. https://doi.
org/10.1186/s12981-015-0044-0

16. Kates J, Wexler A, Lief E. Financing the Response to HIV in Low and Middle-income Countries. Menlo Park, Calif.: Kaiser Family Foundation, 2014. http://www.hst.org.za/publications/NonHST\%20 Publications/20130923_KFF_UNAIDS_Financing.pdf (accessed 1 January 2018).

17. Ustianowski A, Arends JE. Tenofovir: What we have learnt after 7.5 million person-years of use. Infect Dis Ther 2015;4(2):145-157. https://doi.org/10.1007\%2Fs40121-015-0070-1

18. Mander M, Ntuli L, Diederichs N, Mavundla K. Economics of the traditional medicine trade in South Africa: Health care delivery. S Afr Health Rev 2007;2007(1):189-196. http://hdl.handle.net/10520/ EJC35482 (accessed 2 January 2018).
19. Bigna JJR, Plottel CS, Koulla-Shiro S. Challenges in initiating antiretroviral therapy for all HIVinfected people regardless of CD4 cell count. Infect Dis Poverty 2016;5(1):85. https://doi.org/10.1186/ s40249-016-0179-9

20. Nansseu JR, Bigna JJ. Antiretroviral therapy related adverse effects: Can sub-Saharan Africa cope with the new 'test and treat' policy of the World Health Organization? Infect Dis Poverty 2017;6(1):24 https://doi.org/10.1186/s40249-017-0240-3

21. World Bank. World development indicators. https://data.worldbank.org/data-catalog/worlddevelopment-indicators (accessed 1 January 2018).

22. National Treasury, South Africa. 2017 budget speech. http://www.treasury.gov.za/documents national\%20budget/2017/speech/speech.pdf (accessed 1 January 2018).

Accepted 12 December 2017. 